\title{
Economía Política Cultural: Una nueva propuesta teórica para el estudio de la economía y la cultura
}

\author{
L. Iván Valenzuela Espinoza \\ Universidad Arturo Prat, Iquique, Chile. \\ Email: leandro.valenzuela@unap.cl
}

\begin{abstract}
Resumen: El presente artículo tiene como objetivo principal exponer y analizar una reciente propuesta teórica, cuya contribución consiste en ofrecer una mejor comprensión de las relaciones entre economía y cultura en las sociedades contemporáneas, con particular énfasis en las de América Latina. De forma decisiva, fenómenos y procesos como la globalización, la transformación del Estado, la gobernanza, la proliferación escalar, entre otros, redunda en nuevas configuraciones entre economía y cultura. A tal efecto, se expone el "enfoque estratégicorelacional” del sociólogo Bob Jessop en tanto que fundamento conceptual para la investigación de dichas configuraciones. A partir de premisas estratégicorelacionales, el análisis se centrará en la capacidad teórica y heurística de la Economía Política Cultural, la cual precisamente toma como objeto de estudio las relaciones y los fenómenos entre economía y cultura. El enfoque en cuestión será aplicado a debates latinoamericanos relativos, por ejemplo, a los bienes comunales urbanos y la ciudad.
\end{abstract} ecológico.

Palabras clave: economía política cultural, semiosis, Estado, dominio

\section{Cultural Political Economy: a new theoretical proposal for the study of economy and culture}

\begin{abstract}
This article has as its main objective the presentation and analysis of a recent theoretical approach whose contribution consists in a better understanding of the relations between economy and culture in contemporary societies, especially in those of Latin America. In decisive ways, phenomena and processes such as globalization, State transformation, governance, the scalar proliferation, among others, produce new configurations between economy and culture. Accordingly, a theoretical framework is put forward, that is, sociologist Bob Jessop's “strategic-relational approach” which provides conceptual foundations for the research of the relations and dynamic between economy and culture. Starting from "strategic-relational” premises, the analysis will center on the theoretical and heuristic potential of Cultural Political Economy which has as its subject matter precisely the relations between them. Thus, this new approach will be applied to Latin American debates related to, for example, the urban communal goods and the city.
\end{abstract}

Key words: cultural political economy, semiosis, State, ecological dominance. 


\section{Economia Política Cultural: Uma nova proposta teórica para o estudo da economia e da cultura}

Resumo: O presente artigo tem como objetivo principal expor e analisar uma recente proposta teórica, cuja contribuição consiste em proporcionar uma melhor compreensão das relações entre economia e cultura nas sociedades contemporâneas, com ênfase particular na América Latina. Fundamentalmente, fenômenos e processos como a globalização, a transformação do Estado, a governança, a proliferação escalar, entre outros, resultam em novas configurações entre economia e cultura. Para este fim, se expõe o enfoque "estratégico relacional” do sociólogo Bob Jessop enquanto base conceitual para a pesquisa de tais configurações. A partir de premissas estratégico-relacionais a análise se centrará na capacidade teórica e heurística da Economia Política Cultural, que tem precisamente como objeto de estudo as relações e os fenômenos entre economia e cultura. A abordagem em questão será aplicada a debates latino-americanos sobre, por exemplo, os bens comunais urbanos e a cidade. ecológico.

Palavras-chave: economia política cultural, semiose, Estado, domínio

\section{Introducción}

Pese a la relevancia de las relaciones entre economía y cultura, éstas a menudo no han sido abordadas de manera sistemática y profunda a tono con la extrema complejidad de nuevos fenómenos sociales. Ante esta situación, los distintos enfoques convencionales de la economía política, la sociología y las ciencias sociales suelen carecer de la innovación necesaria para las actuales exigencias conceptuales. Lo anterior, por cierto, conlleva el riesgo de empobrecer la comprensión de la cultura, la economía y de la dinámica social en su conjunto. De manera específica, se torna necesario contar con marcos teóricos que estén en condiciones de dar cuenta de la confluencia entre economía y cultura en numerosas y cruciales instancias de las formaciones sociales contemporáneas. Así, se argumentará a favor del "enfoque estratégico-relacional" como base intelectual para la emergente de Economía Política Cultural, que precisamente toma como objeto de estudio las complejas relaciones entre economía y cultura, proponiéndose una modalidad de diálogo teórico capaz de arrojar luz sobre importantes debates en América Latina.

El artículo consta de tres secciones. En la primera serán expuestos el “enfoque estratégico-relacional y sus principios centrales. A continuación, el análisis ilustrará los aportes y alcances de la Economía Política Cultural en tanto propuesta teórica. La última sección, a su vez, aborda desde la Economía Política Cultural los debates que, en el marco de problemáticas latinoamericanas, giran en torno a la economía solidaria/popular, la política económica urbana y los bienes comunales en el contexto de la ciudad y la urbanización. 
En síntesis, los debates aludidos servirán para desmenuzar las relaciones entre la economía y la cultura en diversos ámbitos sociales, confiriendo la debida importancia a ambas, y elaborando una aproximación teórica capaz de avanzar significativamente en esta área del conocimiento.

\section{El Enfoque Estratégico-Relacional}

Bob Jessop, sobre la base de una elaboración constante del materialismo histórico, ha desarrollado, desde hace tres décadas, un programa de investigación (ver Lakatos y Musgrave 1970) sobre la economía política y el Estado conocido como "enfoque estratégico-relacional” (EER) que, además, permite desentrañar dinámicas y procesos decisivos de las sociedades contemporáneas.

Conforme ha evolucionado, el EER no sólo ha centrado sus esfuerzos en el estudio de la economía política y del Estado, sino que ha llegado a constituirse, al lidiar con "problemas ontológicos básicos de la vida social” (Jessop 2007:16), en una auténtica perspectiva heurística para la investigación de las relaciones sociales en general, por lo que sus propuestas son acogidas y debatidas en un vasto espectro de corrientes intelectuales (Jessop 2007).

Como punto de partida, en su investigación de la economía política y el Estado, el EER se desmarca de las perspectivas teóricas que han tendido a reificar y naturalizar al Estado como si éste existiera por encima o fuera de la sociedad (Ibid:5), optando en cambio por un estudio crítico del mismo como un conglomerado de instituciones, aparatos y prácticas que están insertos socialmente e interrelacionados con otros órdenes institucionales y prácticas sociales.

En tal perspectiva, la manifestación concreta del poder del Estado dependerá del cambiante equilibrio de fuerzas involucradas en la acción política tanto dentro como fuera del Estado. De este modo, el Estado es una "relación social” en función de la cual las relaciones de poder son "condensadas" y "materializadas" precisamente a través del conjunto de instituciones y centros de poder que lo conforman (Ibid:52-53).

En síntesis, el Estado es un sistema dinámico en el que se despliega una compleja dialéctica de estructuras y estrategias relacionadas entre sí (Hay 2002:63). La "selectividad estratégica” (Jessop 2007:35) del Estado confiere gran importancia a las estrategias políticas en sociedades modernas caracterizadas por un creciente policentrismo, que resulta de la consolidación de muchos sistemas funcionales operativamente autónomos con sus propios códigos y programas ${ }^{1}$ (Ibid: 35 ), los cuales, sin embargo, se vuelven más interdependientes materialmente. Como resultado de la incesante diferenciación funcional de dichos sistemas sociales, la complejidad social no hace más que aumentar de forma intensa en las sociedades modernas. 
El intrincado cruce de estructuras y estrategias, en el que se incrusta el Estado, se ve reflejado en el carácter intensamente "relacional” del EER, haciendo necesario un "análisis de las relaciones entre diferentes relaciones que comprenden la formación social” (Jessop 1982:252). Así, el enfoque estratégico-relacional conduce la investigación científico-social del Estado hacia una teoría de la sociedad en toda regla.

\section{Sistema económico y Estado: el dominio ecológico.}

La separación institucional entre Estado y economía de mercado, en tanto que rasgo característico de las sociedades capitalistas, desemboca en lógicas institucionales y modos de cálculo diferentes, y potencialmente contradictorios, en el Estado y la economía. Esto quiere decir que no hay certeza de que los resultados políticos puedan servir a las necesidades del capital.

Como aseveran, entre otros, Block y Evans (2007), la implicación del Estado en la economía no se circunscribe a una función secundaria que corrige o suaviza los efectos de un mercado pretendidamente autosuficiente, sino que se traduce en acciones imprescindibles para el funcionamiento de los mercados y la economía.

La intervención del Estado tampoco se reduce a aspectos meramente “técnico-económicos", puesto que ésta también tiene lugar en contextos políticos que dicen relación con la legitimidad del Estado y los gobiernos, así como con la cohesión social dentro de una formación social ${ }^{2}$ (Jessop 2008).

Con todo, un reto teórico crucial consiste en reconocer el papel especial que desempeña el sistema de economía de mercado en una sociedad policéntrica que presenta altos niveles de complejidad. Tal necesidad se ha hecho más evidente dado el fuerte ascenso del neoliberalismo y la “globalización” en décadas recientes. Por consiguiente, el sistema económico es redefinido en términos estratégico-relacionales a partir del concepto de “dominio ecológico" del capitalismo.

El “dominio ecológico”, en el ámbito de los sistemas sociales, se refiere a "la capacidad estructural y estratégica que posee un determinado sistema en una ecología autoorganizativa de sistemas para imprimir su lógica de desarrollo al funcionamiento de otros sistemas, capacidad mucho mayor que la que poseen dichos sistemas para imponerle a él sus respectivas lógicas” (Jessop 2008:29). Esta capacidad siempre está mediada por las lógicas operativas de otros sistemas y las racionalidades comunicativas propias del "mundo de la vida”, cuya riqueza de principios, valores culturales y lógica no está anclada en ningún sistema social en particular, al tiempo que sustenta la interacción social de la vida cotidiana (Ibid: 63).

Pero, aún cuando las condiciones favorecen el dominio ecológico de largo plazo de la economía capitalista, otros sistemas pueden adquirir pri- 
macía de corto plazo en respuesta ante crisis de otros lugares, reforzando la idea de que ningún sistema individual puede pretender representar ni sustituir al todo. Dado que cada sistema autopoiético es operativamente autónomo y sustantivamente interdependiente con otros sistemas a la vez, incluso un sistema ecológico dominante depende del rendimiento socialmente adecuado de otros sistemas (Ibid:33). Esto impacta de lleno, por cierto, en la forma que adopta la gobernanza en términos de coordinación de los diferentes sistemas sociales autopoiéticos de la formación social, los cuales operan en un proceso de “proliferación escalar”, es decir, haciéndose presente no sólo en la escala nacional, sino que también en la subnacional y la supranacional.

Como resultado, la noción de dominio ecológico de la economía en las sociedades complejas se opone frontalmente a la tendencia neoliberal a sobredimensionar el rol de la economía, la cual le atribuye facultades de determinismo arrollador sobre el Estado, la política y el conjunto de la sociedad. Tal conclusión, por cierto, también aparece en otros enfoques críticos que rechazan el "fundamentalismo de libre mercado" de la economía neoclásica (ver, Block y Evans 2007).

En resumen, la economía debe ser entendida de forma sensiblemente más amplia de lo que sucede en los análisis económicos convencionales. Asimismo, lo económico también es constituido por factores y procesos extraeconómicos (Polanyi 1992), comprendidos los culturales, y, por último, hay sendas limitaciones a la determinación económica de la sociedad en la medida que existen contradicciones estructurales y dilemas en la economía capitalista (Jessop 2008:3).

Las consideraciones teóricas anteriores proporcionan bases conceptuales que hacen viable abordar coherentemente las complejas relaciones entre economía y cultura desde la novedosa Economía Política Cultural.

\section{La Economía Política Cultural: una nueva propuesta teórica}

Resulta necesario puntualizar que la Economía Política Cultural de B. Jessop no es la única propuesta seria existente, ya que, por ejemplo, Du Gay y Pryke (2002) y Ray y Sayer (1999) también han hecho contribuciones importantes en esta área del conocimiento, constatándose incluso sugerentes paralelismos temáticos con la Economía Política Cultural estratégicorelacional. Sin embargo, la versión que se elabora aquí resulta altamente llamativa, especialmente por sus firmes bases teóricas, poder analítico e idoneidad para lidiar con problemáticas latinoamericanas que serán expuestas más adelante.

En tal perspectiva, se debe reiterar que importantes fenómenos económicos conllevan sendos desafíos conceptuales y analíticos que han de ser encarados y tratados desde nuevas aproximaciones teóricas (Jessop, Sum 2001; Jessop, Sum 2006). Es más, crecientemente se toma conciencia 
de los severos problemas de índole teórica que enfrentan las propuestas disciplinarias convencionales (Ibid: 2006). Por lo mismo, en el campo de la economía política destacan distintos esfuerzos teóricos por dar cuenta de dichas realidades, a saber, la globalización, la transformación del Estado, la proliferación de escalas, la gobernanza, la economía del conocimiento, la innovación, etc. Es precisamente en este entramado de desafíos donde el enfoque estratégico-relacional brinda un soporte teórico y heurístico a sofisticadas innovaciones para la economía política crítica (Ibid), entrañando una inequívoca apertura transdisciplinaria que, como se ha visto, considera, entre otros, el papel del Estado, la complejidad de los sistemas autopoiéticos y de las diferentes escalas y la gobernanza.

Ahora bien, a partir de lo indicado se sentaron las bases para el desarrollo de una versión estratégico-relacional de Economía Política Cultural (EPC) ${ }^{3}$ (Jessop 2008, 2009). En efecto, Bob Jessop, en activa colaboración con la politóloga Ngai. L. Sum, asumió el "giro cultural”, otorgando la mayor importancia a los discursos, la identidad, la reflexividad y la creación de significado (Jessop, Sum 2001; Jessop, Sum 2006), enfatizando el papel que cumplen elementos tanto materiales como discursivos en la constitución de estrategias económicas y modelos de desarrollo, los cuales inciden en la conformación de los fenómenos económicos y en cómo son comprendidos y teorizados. Así, la EPC se está convirtiendo en un emergente enfoque crítico y auto-reflexivo de la economía política que subraya la inevitable historicidad y contextualidad de sus planteamientos y conocimiento, rechazando de plano las implicancias reificadoras y naturalizadoras de enfoques convencionales sobre la economía y los mercados (Jessop, Sum 2001, 2006).

Siguiendo a D. Harvey (2003: 17, 24-31), podemos entender el "giro cultural” a la luz de dos características básicas. Por una parte, a contar de las décadas de 1960 y 1970 hubo una crítica intelectual heterogénea al insuficiente interés prestado a la cultura en corrientes de pensamiento de la época, como, por ejemplo, el marxismo estructuralista y la economía política convencional. No obstante, en dichas décadas se consolidó la sociedad de consumo en el capitalismo avanzado, al tiempo que la cultura comenzó a desempeñar un protagonismo más central en la reproducción de la misma (Short 2006). Los más variados ámbitos de la dimensión cultural, como, por ejemplo, la publicidad, el diseño y las tecnologías de la información y la comunicación, asumieron un papel directo en la economía, la educación, la socialización, el ocio, etc. Por consiguiente, el "giro cultural” llamó a prestar la mayor atención en el plano intelectual y político a la relevancia de la cultura para el conjunto de la sociedad. De otra parte, en su modalidad postmodernista extrema, el "giro cultural” estableció una dicotomía excluyente entre los temas emergentes de la identidad, la etnicidad, el género, entre otros, y las categorías de análisis de clase y de la economía política crítica, especialmente las de raigambre marxista.

De este modo, la Economía Política Cultural de Jessop debe entenderse como un intento dialéctico de reconocimiento y apertura a la impor- 
tancia de la cultura, que, sin embargo, es articulada con la tradición de economía política crítica fundada por Marx.

Es posible indicar ciertos rasgos distintivos en la EPC estratégicorelacional que la diferencian notoriamente de otras formulaciones (Jessop 2009:336-7). En primer lugar, el "giro cultural”, de entrada, se relaciona íntimamente con la economía política, en la perspectiva de la necesidad planteada por la reducción de la complejidad. Dada la extrema complejidad de los entornos económicos, los actores económicos requieren de información, relatos, analogías y metáforas económicas que disminuyan la complejidad en cuestión, permitiéndoles orientarse en escenarios inciertos para la toma de decisiones. Asimismo, la EPC enfatiza la co-evolución e interdependencia de lo semiótico y lo extra-semiótico, prestando importancia tanto a factores discursivos como materiales. Esto quiere decir que no basta con explorar los significados subjetivos de los actores económicos, sino que también es indispensable desentrañar los fenómenos y procesos materiales concomitantes. Por otro lado, propone comprender las relaciones entre economía y cultura descartando el reduccionismo explicativo del "economicismo" y del "culturalismo", y subrayando que ningún conjunto de relaciones sociales por si solo abarca toda la sociedad. Por último, la EPC apunta, dado su origen en el materialismo histórico, a la "desnaturalización” de los imaginarios económicos y políticos, con lo cual se constituye en aporte a la crítica de la ideología y de "formas específicas de dominación" (Ibid:337). A modo de ejemplo, la EPC aspira a poner al descubierto la reificación que hace de los mercados la teoría económica neoclásica, y que suele tener como consecuencia que no se exploren e impulsen formas alternativas para organizar la economía y los mercados.

Dada "la naturaleza fundacional del significado y de creación de significado en las relaciones sociales" (Ibid), la EPC no aspira simplemente a sumar sin más la cultura a la economía, o a la política, como si cada uno de estos ámbitos constituyera una instancia separada de la vida social. Muy por el contrario, la EPC pone el acento en "la naturaleza semiótica de todas las relaciones sociales", postulando que la semiosis, en tanto "producción intersubjetiva de significado" (Ibid), opera, entre otras cosas, como mecanismo crucial para la reducción de complejidad aludida.

Así, el funcionamiento del imaginario económico presupone la existencia de procesos y relaciones económicas sustantivas como componentes propios. En palabras de Jessop (Ibid): “Los imaginarios económicos identifican, privilegian y buscan estabilizar algunas actividades económicas de la totalidad de las relaciones económicas y transformarlas en objetos de observación, cálculo y gobernanza. De este modo le dan a la economía fronteras específicas, condiciones de existencia, agentes económicos típicos, tendencias y contra-tendencias y una dinámica global distintiva”.

La EPC hace suya enfáticamente la idea de que la reducción de complejidad entraña aspectos semióticos y estructurales. Por esta razón, por ende, sostiene que lo "cultural" y lo "social" han de ser concebidos como 
“momentos dialécticamente relacionados del mundo social” (Ibid). De esta manera, lo cultural apunta preferentemente a la creación de significado y a las propiedades resultantes de discursos y otras expresiones discursivas, al tiempo que lo social cabe ser entendido como los "rasgos extra-semióticos de las prácticas sociales y las propiedades resultantes de la interacción social” (Ibid). Lo anterior guardaría relación, por ejemplo, con la cohesión social, la integración social, lógicas institucionales, etc. Es menester, por tanto, estudiar tanto la articulación como la disyunción entre el momento social y el momento cultural.

Paralelamente, y dado el potencial de variación infinita de las interpretaciones económicas, resulta relevante ahondar en cómo su selección y retención son moldeadas no sólo por aspectos intrínsecamente semióticos, sino también por "rasgos emergentes no semióticos de la estructura social" (Ibid), entre otros, por ejemplo, la materialidad de las fuerzas productivas y la tecnología, despuntando el papel central de la referencia externa. Esta, por cierto, pone de manifiesto las constricciones del mundo natural y social, a la vez que enfatiza la importancia de las prácticas materiales. Tales condiciones materiales, de hecho, hacen posible la semiosis y su efectividad (Ibid).

Las premisas teóricas expuestas contribuyen a superar las conocidas formulaciones de estructuralismo y determinismo social que reducen al agente y a las acciones a la condición de meros portadores de estructuras sociales que se auto-reproducen y auto-transforman. Por otro lado, la EPC va más allá de las limitaciones, muy en boga en los últimos años, de una suerte de "imperialismo sociológico del constructivismo social radical", conforme al cual la realidad social se reduce a "los significados y comprensiones de los participantes acerca de su mundo” (Ibid:340). En pocas palabras, la EPC ofrece una propuesta que subraya la necesidad de investigar la dialéctica entre el ámbito extra-semiótico emergente de las relaciones sociales y el papel constitutivo de la semiosis.

Así entonces, la EPC afirma que al procederse al estudio de la economía esta no debe ser diluida en vagas generalidades acerca de la vida social y cultural que no dan cuenta de su especificidad (Jessop 2004:143), tal como suele suceder en abordajes “culturalistas” de la economía. Sin embargo, la EPC crítica con firmeza el “economicismo” presente, por ejemplo, en las teorías económicas neoclásicas, que terminan reificando las acciones formales y calculadoras que ocurren en el mercado, haciendo caso omiso de las condiciones extraeconómicas que son indispensables para el funcionamiento del mismo (Block y Evans 2007).

En un nítido contraste con las teorías económicas neoclásicas, la EPC insiste en que la economía y los mercados siempre son construidos socialmente de manera históricamente específica (Jessop 2004: 144). Asimismo, pone el acento en el papel clave que cumplen los discursos y las prácticas discursivas en la formación de los sujetos y de las subjetividades, comprendiendo las interpretaciones y las decisiones de los actores 
económicos en los diferentes mercados y en la actividad económica en un sentido amplio, incluida su dimensión simbólica.

\section{Localismo y universalismo flexible}

Los problemas que giran en torno a las relaciones entre economía y cultura aparecen en los debates latinoamericanos sobre la economía solidaria/popular, la economía política urbana y los bienes comunales urbanos. Sin embargo, una premisa analítica indispensable para avanzar en dichos debates exige la superación dialéctica de la oposición rígida entre, por un lado, los planteamientos que enfatizan lo "local" y los que, por el otro, otorgan prioridad a lo "universal”.

Dicha necesidad de superación se apoya en la idea de que el conocimiento, pese a ser local y contextual, en modo alguno debe ser concebido de manera relativista como ha ocurrido en la modalidad postmodernista del "giro cultural". De acuerdo con el realismo crítico, reconocer el proceso de construcción social del conocimiento para nada implica que este termine viéndose reificado, puesto que el conocimiento universal flexible permite diálogo, debate y adaptaciones mutuas entre conocimientos locales y diferentes (ver, por ejemplo, Sayer 2000).

Así entonces, la EPC, de forma congruente con el realismo crítico, hace posible resolver el atolladero identificado por David Harvey (2003), quien, por un lado, apoya con entusiasmo cómo el "giro cultural", que pretende resaltar el protagonismo de la cultura en la vida social, ha revitalizado el interés por las especificidades y singularidades culturales de localidades, ciudades, lugares, etc., pero, por el otro, critica con vehemencia cuando este desplazamiento se traduce en un abandono de la economía política y de consideraciones universales, tal como, sucede, por ejemplo, con los derechos humanos y la globalización.

Conforme a Harvey (Ibid: 106): "La fascinación por los “conocimientos locales” (...) y las culturas locales, por la política de "lugar” y de "construcción de lugar" es evidente en todas partes". Esto ha supuesto un gran e importante conjunto de estudios que ponen el acento en dimensiones culturales que dicen relación con "formas de vida, formas de conocimiento, modos de relación y producción social, estructuras socioecológicas y valores y creencias" (Ibid). Asimismo, ha promovido una orientación normativa que destaca "cierto tipo de localismo o comunitarismo" en tanto que "ideal de vida social” por el cual se debería luchar. Desde esta perspectiva, sin embargo, se abandona todo intento serio por definir criterios de justicia, derechos humanos o "desarrollo" de índole universal so pretexto de que tal ejercicio sólo puede traducirse en dispositivo de dominación u opresión. Esta aprensión, como se verá, es altamente pertinente para los debates en América Latina acerca de la "economía solidaria/popular”, el "desarrollo alternativo” y las “alternativas al desarrollo” (Santos, Rodríguez, 2011).

Cabe subrayar que la EPC también concuerda de plano, en este ám- 
bito, con el análisis de Harvey (2003:105), quien descarta las formulaciones de universalismo de índole abstracta que van asociadas a expresiones de poder y dominación. Sin embargo, el autor, en consonancia con la EPC, llama a rescatar las versiones de universalismo que "descansan firmemente en la experiencia local”, y que se refuerzan con un sólido "arraigo de las formas culturales locales” (Ibid:107). El consiguiente debilitamiento de la oposición rígida entre "particularismo” y "universalismo” hace factible abogar por "formas de ensanchar y ampliar el ámbito de los derechos humanos de manera tan fiel como sea posible al derecho a ser diferente o al "derecho a la producción de espacio” (Ibid:108).

Como se ha visto, la recuperación de las culturas locales no tiene porqué traducirse en un quiebre con las propuestas de universalismo flexible y las temáticas propias de la economía política.

En suma, la EPC, al igual que muchos otros enfoques, sostiene que la economía y los mercados en un sentido amplio presuponen condiciones, procesos y factores extra-mercado y extraeconómicos (Jessop 2004:147). La economía simplemente no puede ser entendida ni administrada como ámbito económico "puro" y "separado” que funciona y se reproduce con independencia de los ámbitos sociales no económicos (Polanyi 1992). Tampoco se puede considerar que la economía determine de manera unilateral los ámbitos no económicos (Jessop 2004: 147).

\section{Repensando la economía solidaria/popular, la economía política urbana y los bienes comunales en el marco de la ciudad y la urbanización}

En varios aspectos, los efectos de décadas de un movimiento de políticas neoliberales en el mundo de forma general, y en América Latina en particular, han visto la desigual activación de una suerte de contramovimiento de incrustación social de los mercados, que se ajusta en gran medida al conocido análisis de Karl Polanyi (1992). En lo medular, el pensador húngaro detalló cómo el movimiento de laissez-faire en Inglaterra, en el siglo XIX, generó un complejo contramovimiento de protección de la sociedad mediante leyes e instituciones sociales y laborales, que, a la larga, conllevaron la incrustación social de los mercados, mitigando significativamente sus efectos más nocivos y ampliando políticamente las posibilidades para organizarlos y moldearlos de manera diferente. A juicio de Polanyi (Ibid:183-4, 227), la defensa de la sociedad fue mucho más allá de la resistencia clasista y asumió una gran variedad de expresiones, siendo especialmente importantes la implicancias económicas de la corriente cooperativista de R. Owen, dada su contribución a la lógica de protección social en medio de una economía de mercado tensionada y cambiante.

Por consiguiente, una idea crucial de lo expuesto es que los mercados y las instituciones económicas han de ser entendidos como profundamente incrustados o insertos en concomitantes bases sociales (Evans 1995). 
De forma altamente compatible con Polanyi, los debates latinoamericanos que serán considerados a continuación pueden entenderse a la luz de una suerte de contramovimiento de incrustación social de los mercados y de la economía.

El marco teórico que ofrece la EPC para avanzar en dichos debates se centra, entre otros aspectos, en las relaciones entre economía y cultura, en el desarrollo analítico del concepto de incrustación social, al tiempo que sirve para prestar atención a los desafíos al neoliberalismo en el subcontinente, y que toman cuerpo en un contramovimiento de protección social en distintos lugares, tal como se desprende de la obra de K. Polanyi.

\section{La economía solidaria/popular}

Una característica central del actual dinamismo político y social de varios países de América Latina obedece a un proceso de crítica y resistencia de amplios sectores sociales a la hegemonía neoliberal desde la década de 1980 en adelante bajo el "Consenso de Washington" (Santos 2005: 23-4). En otras palabras, tras el movimiento de globalización neoliberal que impuso su hegemonía en el subcontinente, se ha desatado un contramovimiento de protección de la sociedad que se inserta en un marco mucho más amplio de lucha a favor de una "globalización contra-hegemónica" (Ibid: 84), que subraya la necesidad de dar impulso mundial a leyes, prácticas e instituciones económicas alternativas que hagan posible la incrustación social de los mercados. Entre los ejemplos de alternativas de producción, que suelen ser estudiados, se encuentra el reciente resurgimiento del movimiento cooperativista de trabajadores, particularmente en la provincia de Québec, el cual ha forjado lazos asociativos con pequeñas y medianas empresas, instancias estatales, instituciones financieras locales y agentes de la sociedad civil (Block, Evans 2007: 330). Conforme a Block y Evans (Ibid), el cooperativismo, dadas ciertas condiciones, puede ser entendido como una forma alternativa relevante de organización de la producción, la economía y los mercados. Dicha aseveración, como se ha visto, se ubica en la línea de análisis de K. Polanyi.

Ahora bien, y en relación al notable interés por "formas cooperativas de producción”, "economías populares” y "desarrollo alternativo", acompañado de la búsqueda de "alternativas al desarrollo" (Santos, Rodríguez 2011:16-44), se constata la aparición de nuevos enfoques conceptuales que, en definitiva, desde los debates en torno al desarrollo y la economía en América Latina (Coraggio 2013; Elizalde 2013), son susceptibles de ser abordados desde la EPC. Propongo específicamente reforzar el fundamento conceptual de dichos debates a partir del enfoque estratégicorelacional y de su correspondiente economía política cultural.

Por consiguiente, y en primer lugar, en sus actuales reformulaciones, el cooperativismo exhibe una teoría social implícita que subraya "la defensa de una economía de mercado con principios no capitalistas de cooperación y mutualidad", el realce de la sociedad civil y el cuestionamiento a la rigidez 
de la jerarquía y centralismo del Estado (Ibid:23). Simultáneamente, se sostiene que las actividades económicas concretas y prácticas deben dar cuenta de "valores de autonomía, democracia participativa, igualdad, equidad y solidaridad” (Ibid).

Asimismo, las cooperativas, pese a ser entendidas en marcos de significados referidos a "alternativas emancipadoras de producción" (Ibid:25), son instituciones económicas con potencial de adecuarse a las exigencias de competitividad de la economía global posfordista. A este respecto, Santos y Rodríguez identifican cuatro características sobresalientes (Ibid:25-6). En primer término, las cooperativas siempre han operado con vistas a competir en los diversos mercados aún cuando se hayan guiado conforme a valores y principios no capitalistas. Asimismo, hay claros ejemplos de cooperativas que han resultado ser productivas y eficientes, especialmente en las instancias organizativas donde los incentivos económicos han sido compatibles con un elevado compromiso colectivo y ético. Incluso hay experiencias altamente llamativas que han tenido lugar en entornos locales de notable sofisticación tecnológica y productiva. Por otro lado, y especialmente en América Latina, las cooperativas de trabajadores han sido capaces de logros promisorios en rendimiento económico y disminución de la desigualdad entre sus integrantes. Por último, la conexión entre estas instituciones, sus prácticas solidarias y determinados mercados ha redundado en que la democracia participativa se haga presente en la empresa y el principio de ciudadanía en la gestión empresarial (ver, por ejemplo, Quijano 1998).

De otra parte, las propuestas de "desarrollo alternativo"4, que son formuladas a contar de las décadas de 1980 y 1990, son extraordinariamente variadas y tienden a reflejar el descontento con modelos de desarrollo que marcaron las estrategias económicas seguidas por gran parte de los países en vías de desarrollo (Kiely 1995). Con todo, hay ciertas ideas centrales que caracterizan al “desarrollo alternativo". Dado lo anterior, se parte con una tajante crítica al reduccionismo economicista y tecnocrático presente en los modelos dominantes de desarrollo (Coraggio 1995). Así, “contra la idea de que la economía es una esfera independiente de la vida social, cuyo funcionamiento requiere del sacrificio de bienes y valores no económicos-sociales (igualdad), políticos (participación democrática), culturales (diversidad étnica) y naturales (el ambiente)- el desarrollo alternativo subraya la necesidad de tratar la economía como parte integrante y dependiente de la sociedad y de subordinar los fines económicos a la protección de estos bienes y valores” (Santos, Rodríguez 2011:34).

Otra característica de este enfoque pone el acento en el rechazo a la preferencia excluyente por el crecimiento económico por encima de otras consideraciones (Max Neef et al. 1993). Por lo mismo, plantea que el crecimiento económico debe reconocer la existencia de límites y que éste debe estar supeditado a dimensiones sociales, culturales, ambientales, etc., reivindicando la importancia de valores como la igualdad y la ciudadanía (Santos, Rodríguez 2011:34). Simultáneamente, y desde su apuesta por un enfo- 
que de “abajo hacia arriba”, se arguye a favor de la escala local y comunitaria como componente central de las distintas propuestas de desarrollo. Finalmente, varias de estas experiencias, particularmente en América Latina, propiciaron la creación de "empresas y organizaciones económicas populares de propiedad y gestión solidaria”, en clave de autogestión y poder comunitario, reñidas con la separación entre capital y trabajo así como con el Estado, dado su carácter jerárquico y centralizador (Ibid:35).

Finalmente, la tesis de “alternativas al desarrollo” (Ibid:45), sostiene que es la idea de “desarrollo” en sí la que debe ser descartada, dada su carga eurocéntrica, decantándose por un enfoque "posdesarrollista” (Viola et al, 2000). En tanto que expresión del "giro cultural”, esta aproximación reivindica las expresiones culturales e identitarias locales de diferentes comunidades que han sido ignoradas o dominadas, imponiéndoseles patrones culturales uniformes y ajenos de naturaleza opresiva (Escobar 1995). Conforme a esta perspectiva, hoy en día, para mujeres, pueblos originarios, campesinos, etc., se debe abogar por la "recuperación de formas de entender el mundo que fueron marginadas por el modelo dominante, en las cuales las actividades económicas son solamente una parte de un conjunto de prácticas culturales a las que están subordinadas” (Santos, Rodríguez 2011:41). En suma, la opción para las comunidades en cuestión pasa por la "reivindicación de la diversidad cultural y de la diversidad de formas de producir y de entender la producción, que existen hoy por todo el mundo, a pesar de la expansión de la economía capitalista y de la ciencia moderna" (Ibid).

En su notable análisis, Santos y Rodríguez (Ibid: 49-59) adelantan un conjunto de alcances conceptuales que deberían hacer avanzar la investigación de las tres corrientes expuestas arriba. En tal perspectiva, sostengo que algunos de éstos, a lo que se hará mención, son claramente análogos y teóricamente compatibles con la EPC y los principios estratégicorelacionales.

En primer lugar, Santos y Rodríguez (Ibid: 49) arguyen que las “alternativas de producción” no son únicamente económicas, y que su éxito pasa por una integración con "procesos culturales, sociales y políticos". En segundo lugar, se argumenta que las “alternativas de producción” deben ser incrustadas y apoyadas por "redes de colaboración y ayuda mutua” (Ibid: 51). Asimismo, se hace hincapié en el dilema que supone el Estado, ya que abogan por impulsar las alternativas en cuestión tanto dentro como fuera del mismo (Ibid: 52-3). Por último, Santos y Rodríguez (Ibid: 534) destacan, más allá del localismo, que las reformas planteadas han de ser capaces de operar en una amplia gama de escalas.

En su conjunto, las ideas examinadas arriba se sitúan en una perspectiva que, en términos de la EPC estratégico-relacional, cuestiona e impugna la ampliación de la lógica de acumulación de capital a la sociedad en su conjunto (Jessop 2008:322), procurando apuntalar el "valor de uso social "y reinsertando el mercado conforme a lógicas sociales (Ibid), con 
lo cual cuenta con potencial contrahegemónico para contrarrestar la propagación neoliberal de la forma mercancía ${ }^{5}$. En otras palabras, la apropiación selectiva que hacen Santos y Rodríguez (2011) de las tres corrientes que analizan, pese a sus diferencias, se sitúan en el campo de prácticas sociales que regulan y moldean los mercados y la actividad económica, limitando el dominio ecológico del sistema económico en el conjunto de la sociedad. En los tres casos se identifican relaciones entre economía y cultura en un contexto social más amplio, razón por la que se torna imprescindible teorizar las características del mismo.

En efecto, la EPC ofrece un marco teórico sólido ya que investiga las configuraciones entre economía y cultura en un contexto mayor de sistemas sociales autopoiéticos que se diferencian funcionalmente al interior de la formación social. Esto quiere decir que en tales configuraciones inciden de manera decisiva las instituciones y prácticas de los distintos sistemas sociales, como el político, el judicial, el educacional, el religioso, etc. Asimismo, proporciona una base conceptual desde la cual se explora seriamente el papel del Estado en el conjunto de la formación social. Paralelamente, elabora y enriquece la teorización acerca de la incrustación social de la economía, la producción y los mercados, lo cual contribuye tanto a la comprensión de los límites del dominio ecológico neoliberal en América Latina como a la búsqueda de formas económicas alternativas y más democráticas. Finalmente, otra fortaleza de la EPC estratégico-relacional es el conocimiento que brinda sobre la proliferación de escalas espaciales, conectándolo con las discusiones relativas a la gobernanza y las redes.

\section{La economía política urbana}

De otra parte, un importante cuerpo teórico ha investigado, en los últimos años, el fuerte cruce entre economía y cultura en el contexto urbano de las economías de mercado de las sociedades contemporáneas (Scott 2000; Short 2006; Ribera Fumaz 2009).

Dado que un conocimiento más acabado de la ciudad y de los procesos urbanos conlleva profundizar en sus procesos socioeconómicos más amplios, la economía política crítica ha proporcionado gran ayuda analítica para descifrar las complejidades concomitantes (Short 2006:92).

Cabe enfatizar que, en formas anteriores de economías y sociedades capitalistas, y desde mucho antes, el consumo se limitaba a sectores acomodados y privilegiados de la sociedad (Ibid). No obstante, y de la mano de la versión neoliberal de la globalización, el consumo de masas ha adquirido nuevos bríos, al punto de consolidarse incluso en sociedades en desarrollo, como las latinoamericanas. Dicho proceso ha propulsado la producción de espacios urbanos, la cual, a su vez, se ha visto reforzada por éste. Las ciudades latinoamericanas dan cuenta explosivamente de centros comerciales, multitiendas, supermercados, recintos feriales y de exposiciones, festivales y “malls”. Cómo no, lo anterior ha sido fuertemente impulsado por capitales y empresas varias vinculadas a la tenencia de suelo, el crédito, 
la construcción y la actividad inmobiliaria. La dinámica descrita es un componente clave, entre muchos otros, de una "nueva transición urbana" en América Latina a comienzos del presente siglo (ver, ONU-Habitat 2012).

En consecuencia, se consolida la propensión hacia un estilo de vida asociado a la dinámica descrita que profundiza el consumo, apuntalando tendencialmente formas de sociabilidad, subjetividades y concepciones mentales proclives al hedonismo e individualismo exacerbado, que obedecen a una nueva oleada de individualización (Harvey 2010, 2012).

A decir de J. R. Short (2006:96): "el sistema de consumo masivo se basa en todo un conjunto de prácticas sociales y políticas. Por ejemplo, ordenamientos de crédito sofisticados promueven una ideología de alto consumo masivo mediante el cual la gente es alentada a comprar y seguir comprando... El desarrollo de galería comerciales, tiendas por departamentos, centros comerciales... y megamalls revelan la larga historia de una cultura de consumo urbano. Además, el consumo es parte tanto de la identidad individual como colectiva,.....Un conjunto de espacios tanto de formas colectivas como personales de consumo caracterizan la ciudad”.

No es de sorprender, entonces, que la ciudad y el espacio urbano se conviertan en el escenario por excelencia para el encuentro entre economía y cultura (Ibid:102) en las sociedades actuales. Dice Short (Ibid): "La cultura es negocio para las ciudades, y sus economías culturales son ahora un sector económico mayor”. Esto queda de manifiesto, por ejemplo, en el contexto latinoamericano, en los actuales cambios urbanos de Rio de Janeiro que son objeto de crítica por los megaeventos que albergará en los próximos años, sobresaliendo el Mundial de Fútbol de 2014 y los Juegos Olímpicos de 2016, y que están convirtiendo a la urbe en una "ciudad negocio" (Zibechi 2012).

De acuerdo con lo anterior, el entorno construido se revaloriza económicamente relacionándose íntimamente, entre otros, con el consumo cultural, la preservación patrimonial e histórica, las manifestaciones artísticas y estéticas, el turismo cultural urbano y los barrios de interés cultural. Como enfatizan Gottdiener y Hutchison (2006: 16-20), la economía política urbana del capitalismo ha creado vínculos de creciente interdependencia con la industria cultural de la ciudad que gira en torno a espectáculos, museos, congresos, exposiciones, sectores de ocio y diversión, etc.

Por consiguiente, las presiones para que las ciudades se inserten en los flujos internacionales de capital, inversiones, empleos, etc., derivadas de la globalización económica neoliberal, y con la implicación activa del Estado en distintas escalas espaciales, estimulan la puesta en marcha de sendas campañas publicitarias, de relaciones públicas y de marketing (Short 2006:120-25). En síntesis, tales campañas tienen como objetivo bregar en una intensa competencia y rivalidad de discursos, significados, relatos e imágenes donde las ciudades, por decirlo de algún modo, aspiran a tener éxito en la proyección de un ambiente urbano de activa y vibrante actividad 
empresarial que, sin embargo, propicia la calidad de vida urbana junto con dimensiones culturales y artísticas. Todo ello, en su conjunto, debería dar una imagen positiva y agradable, a saber, “cosmopolita”, a la ciudad competitiva (Ibid).

Con todo, de acuerdo con Short (Ibid:124): "las imágenes dominantes representan ciudades libres de conflictos, donde el pluralismo lleva a una variedad de restaurantes étnicos en vez de a una competencia por recursos escasos, donde la vida buena no es estropeada ni afectada por la presencia de pobres y marginados que son excluidos e ignorados. La ciudad buena no es la ciudad justa”. Así entonces, la ciudad marcada a fuego por el neoliberalismo tiende a enfatizar "el consumo individual en vez del bienestar colectivo, el logro privado en vez de la justicia social y la ciudad como placer privado en vez de bien colectivo" (Ibid).

Desde la EPC estratégico-relacional, por tanto, se aportan categorías y conceptos que enriquecen el análisis crítico de la economía política urbana en América Latina, proporcionando el sustrato teórico que explica las configuraciones de relaciones entre componentes económicos y culturales en las ciudades. A modo de ilustración, las dinámicas vistas arriba ponen de manifiesto la proliferación de escalas espaciales, así como las presiones que sufren las ciudades para insertarse en los flujos globales del capital que caracterizan al dominio ecológico del sistema económico en el plano internacional.

\section{Los bienes comunales: la ciudad y la urbanización}

El desarrollo expuesto arriba rápidamente generó toda una literatura crítica que ha desmenuzado sus lógicas y efectos socialmente adversos. Así, una crítica que se ha abierto paso con fuerza dice relación con la propagación, sobre la base de políticas neoliberales en numerosos lugares, de procesos de privatización, vigilancia y controles de las ciudades, pérdida de espacios públicos, deterioro de infraestructura y servicios sociales, que han redundado en el deterioro de los "bienes comunales” urbanos. De hecho, dos connotados exponentes de la teoría social crítica, Michael Hardt y Toni Negri (2009), han subrayado la necesidad de conectar las dinámicas urbanas con la recuperación de los bienes comunales urbanos en el marco de las luchas democratizadoras que impugnan y resisten los embates de la lógica mercantil y del control del Estado.

En consecuencia, Hardt y Negri (Ibid:137-9) ponen el acento en que el bien comunal cultural comprende los lenguajes humanos, las expresiones culturales, las formas de sociabilidad y diversas prácticas sociales, las cuales se construyen colectivamente a lo largo del tiempo, siendo en principio de acceso abierto a todos/as. Particularmente determinante es el papel de los espacios y procesos urbanos en relación al bien comunal cultural (Ibid).

Ahora bien, a lo largo de los procesos de urbanización, la provisión de espacios públicos y de bienes públicos se ha situado dentro de la res- 
ponsabilidad de los Estados en distintas escalas nacionales y locales. En los ámbitos de la salud, la educación y el transporte, por ejemplo, diferentes luchas sociales y políticas, de sectores y clases subalternas, han sido necesarias para enfrentar la propensión del capital y del Estado a definir las ciudades y los entornos urbanos sin tomar en cuenta seriamente la generación de espacios públicos, y bienes públicos, de alta calidad a disposición de la población. Sin embargo, de acuerdo con Harvey (2012:73), es del todo necesario precisar que el bien comunal urbano conlleva la acción política y colectiva de la ciudadanía orientada a la apropiación o creación del mismo.

De hecho siempre existen tensiones, luchas o conflictos en torno a diferentes facetas de la entrega, acceso o calidad de los espacios públicos y de los bienes públicos (Ibid) en las ciudades. A decir del autor (Ibid): "para proteger el bien comunal es a menudo vital proteger el flujo de bienes públicos que sostienen las cualidades del bien comunal. A medida que la política neoliberal disminuye el financiamiento de bienes públicos, también disminuye el bien comunal disponible, forzando a los grupos sociales a buscar otras maneras de respaldar el bien comunal (la educación, por ejemplo)".

De este modo, el atractivo y ambiente de la ciudad, a modo de ilustración, constituye un "producto colectivo de sus ciudadanos", pero es el negocio del turismo el que obtiene el retorno económico y comercial partir de tal bien comunal (Ibid: 74). En definitiva, son los individuos y los grupos sociales los que dan origen al "mundo social de la ciudad", a través de sus actividades diarias y cotidianas, generando el contexto común y compartido en el que llevamos a cabo las distintas facetas de nuestras vidas. Dice Harvey (Ibid): “Aunque este comunal culturalmente creado no puede ser destruido mediante el uso, si puede ser degradado y banalizado mediante un uso excesivo".

Como es sabido, la teoría liberal justifica la existencia de derechos privados de propiedad sobre la base de que éstos contribuyen al bien común o interés general, permitiendo así que haya prosperidad, bienestar, etc. Empero, la política neoliberal ha puesto de manifiesto su inclinación a apropiarse despiadadamente de los frutos del trabajo colectivo, con lo cual se pone en el tapete la necesidad de reflexionar seriamente acerca de la noción de derechos colectivos de propiedad (Ibid: 77-8), a efectos de "hacer frente a los poderes que extraen rentas de la vida común que otros han creado" (Ibid).

En los contextos urbanos, lo descrito se manifiesta, tal como subrayan Gottdiener y Hutchison (2006: 18-21), en una economía política neoliberal que opera a través de rentas del suelo y de la propiedad, moldeando la ciudad de acuerdo con sus intereses. Dice Harvey (2012:78): "Aquellos que crean una vida de barrio cotidiana interesante y estimulante la pierden ante las prácticas predatorias de empresarios de bienes raíces, financistas y consumidores de clase alta desprovistos de toda imaginación social urbana. Cuanto mejor son las cualidades comunes que crea un grupo 
social, más probable resulta que sean asediadas y apropiadas por intereses privados maximizadores de ganancias”. (Ibid).

Por otro lado, también se distingue una forma emergente de cruce entre economía y cultura en lo que guarda relación con cómo la historia, las tradiciones y dinámicas culturales de raigambre local son “absorbidas dentro de los cálculos de la economía política” (Ibid:99), dotando de cierto tipo de "vida simbólica" (Gottdiener y Hutchison 2006: 16) a las ciudades. Este proceso comprende, en el marco de la globalización y, de manera especial, "la resurrección e invención de tradiciones locales” (Ibid), razón por la cual los promotores de la globalización pueden auspiciar diferenciaciones culturales entre ciudades, localidades y regiones. No obstante, como resultado de lo anterior pueden desatarse reacciones políticas incluso antagónicas con las formas concretas que asume la globalización en lugares específicos. A todas luces, dicha situación es fuente potencial de contradicciones, tensiones y dilemas concomitantes.

En consecuencia, además de la “glocalización”, en espacios regionales, suelen activarse actores sociales, políticos y económicos que participan de manera enérgica en la promoción, difusión y “venta” de ciudades y lugares conforme a prácticas de “glurbanización” (Jessop 2007:165-6).

En dichas prácticas las localidades concretamente incorporan a la competitividad componentes extraeconómicos, comprendiendo la infraestructura social, la educación, la salud pública, la calidad de vida, el ocio, los parques temáticos, etc. En otras palabras, la noción de economía, desde estas premisas, se amplía para considerar elementos culturales y sociales en intensa interrelación con el Estado a lo largo de diferentes escalas (Scott 2000, Storper 1997, Ribera-Fumaz 2009).

La literatura pone el acento en el papel central que cumplen las alianzas y coaliciones entre distintos actores en el ámbito del "emprendimiento urbano” que inciden en las relaciones entre lo local y lo global de acuerdo con pautas dialécticas entre “espacio” y "lugar” (Harvey 2012:101-2). Especialmente los modelos de "máquinas de crecimiento urbano” ilustran las tensiones en cuestión, máxime al tener que dar cuenta de éxitos y fracasos en contextos marcados de “desarrollo geográfico desigual” (Harvey 2003), a saber, de localidades, regiones y sociedades con marcadas diferencias en desarrollo, recursos, capacidades, etc. Cabe subrayar, en este ámbito, que el capital cuenta con formas para apropiarse de variaciones culturales locales y de diferencias locales (Ibid 2012:109).

Por lo mismo, y tal como postulan Gottdiener y Hutchison (2006: 7683), de manera congruente con los argumentos estratégico-relacionales de la EPC, es menester rechazar las explicaciones reduccionistas de los procesos urbanos que dan prioridad causal sólo a un conjunto de relaciones sociales, sean estas económicas o culturales. La complejidad que emerge de la glocalización y de la glurbanización refuerza la pertinencia de la EPC, dado que lisa y llanamente el desarrollo de actividades como el turismo, el 
patrimonio, los servicios y el comercio, en suma, la “industria cultural” de la ciudad (Scott 2000), se sustenta en el control del suelo y en inversiones a largo plazo en el "entorno construido” que es fijo y geográficamente inmóvil (Harvey 2012: 101-2). Las categorías de análisis de la EPC proporcionan las bases conceptuales para investigar empíricamente las complejas configuraciones entre economía y cultura señaladas.

Es altamente llamativo cómo la propagación de la globalización neoliberal se ha traducido frecuentemente en que productos y prácticas culturales locales, en la medida que tienen éxito comercial, corren el riesgo de mermar sus características singulares y excepcionales, con lo cual puede debilitarse su distinción y, con ello, sus rentas de monopolio y éxito económico (Harvey 2012:108). Simultáneamente, si persisten rasgos culturales de excesiva distinción y diferenciación, su conversión en negocios viables y rentables puede verse seriamente obstaculizada (Ibid).

De ahí la importancia creciente del marketing, la publicidad y el diseño que entran de lleno a luchar en el plano discursivo y de semiosis en la promoción de ciudades, localidades y regiones. Se desatan, por consiguiente, auténticas "batallas discursivas” (Ibid) en este circuito económico-cultural de la economía de mercado.

Con todo, la lógica misma del capital presupone que siga habiendo diferenciación y expresiones divergentes en el desarrollo cultural local que son susceptibles de redundar, a través de la acción individual y colectiva, en prácticas culturales transgresoras que sean a la vez sustento de creatividad y autenticidad (Ibid:110). Lo anterior implica, asimismo, que constantemente aparecen "espacios para la política transformadora” (Ibid:111) que auguran nuevas posibilidades y potencialidades para la defensa de los bienes comunales urbanos, tal como ponen de manifiesto, en relación a ciudades latinoamericanas, por ejemplo, J. Almeida Lopes (2011), S. Lazar (2010) y R. Zibechi (2012), quienes respectivamente exploran casos de activa participación de movimientos sociales en dinámicas urbanas democratizadoras en Brasil, de experiencias de lucha urbana en contra del neoliberalismo en El Alto (Bolivia), y de las tensiones existentes en Rio de Janeiro entre la lógica mercantil urbana y el desafío contra-hegemónico de las organizaciones sociales.

En suma, la EPC estratégico-relacional amplía y enriquece los fructíferos debates latinoamericanos acerca de alternativas más democráticas para garantizar el derecho pleno de la población a sus espacios urbanos al lidiar con los bienes comunales en las ciudades, tanto como escenario de tensiones y luchas como de manifestaciones económicas y culturales. Esto puede ser entendido como una nítida manifestación del dominio ecológico del sistema económico que, tras activar el movimiento neoliberal, debe encarar el contramovimiento democratizador de incrustación social, donde es clave la dimensión cultural para la recuperación de los bienes comunales. 


\section{Conclusión}

Como se ha visto, urge avanzar en un conocimiento más acabado de las variadas y complejas relaciones entre economía y cultura, máxime al acentuarse las tensiones entre la versión neoliberal de la globalización y las impugnaciones, luchas y resistencia de diversos movimientos sociales, amén de otras expresiones de respuesta crítica. En tal sentido, la Economía Política Cultural, asentada en el enfoque estratégico-relacional de B. Jessop, supone un avance teórico altamente promisorio para el tipo de conocimiento científico-social aludido. Por lo mismo, a partir de distintos fenómenos y procesos sociales se ha demostrado la utilidad teórica y heurística que presta la Economía Política Cultural, superando numerosas dificultades que han trabado el avance de la investigación de la economía y la cultura. Finalmente, se ha mostrado cómo los argumentos estratégico-relacionales y la Economía Política Cultural brindan bases teóricas transdisciplinarias que contribuyen al avance en determinados debates de gran importancia en América Latina. 


\section{Notas}

${ }^{1}$ El enfoque de Jessop es uno de los pocos en la reciente teoría social que recupera y desarrolla, de forma sostenida y rigurosa, la noción de "sistema social” (Walby 2009). Aún cuando se inspira en ciertas ideas de Luhmann, Jessop, sin embargo, dirige el análisis de los sistemas autopoiéticos en una dirección muy distinta, incorporándolo al materialismo histórico, la crítica de la economía política, las relaciones de poder, la agencia humana, etc. (Jessop 2007:27). La apropiación de la teoría de sistemas autopoiéticos en el EER se centra en características básicas de los mismos: autoorganización, auto-reproducción, auto-producción, etc. Los sistemas autopoiéticos coexisten con otros sistemas autopoiéticos, desplegando sendas relaciones de coevolución compleja. Así, los sistemas sociales autopoiéticos exhiben una combinación de autonomía operativa y de interdependencia material.

2 El EER resalta, en una orientación gramsciana, la importancia que tienen las ideas y los discursos, subrayando que las decisiones acerca de políticas económicas y sociales tiene que ver con estrategias de acumulación existentes, proyectos de Estado, proyectos hegemónicos y diferentes visiones de la sociedad.

${ }^{3}$ Para versiones de la Economía Política Cultural distintas a la expuesta aquí, ver Best y Paterson 2010.

${ }^{4}$ En autores como Hettne (1982) y Galtung (1980) se encuentran algunas de las primeras formulaciones del enfoque del "desarrollo alternativo", que incluyen los aportes de organismos internacionales y agencias de ayuda al desarrollo.

${ }^{5}$ Para una valiosa discusión acerca de estrategias económicas orientadas a la superación del neoliberalismo en América Latina ver Coraggio (2013), Cordera (2013) y Elizalde (2013). 


\section{Bibliografía}

Block, F y Evans P. (2007), “El Estado y la economía” en Peter Evans. Instituciones y desarrollo en la era de la globalización neoliberal. ILSA, Bogotá.

Coraggio J.L. (1995), Desarrollo humano, economía popular y educación, AIQUE/Ideas, Buenos Aires.

Ídem (2013),”Otra economía, otra política, otra izquierda”. América Latina en Movimiento 482:1-5.

Cordera, R. (2013), “Utopías realizables: algunas hipótesis de trabajo”. América Latina en Movimiento 482: 10-15.

De Almeida, J. (2011), "El dorso de la ciudad: los sin tierra y la concepción de otro tipo de ciudad” en Boaventura de Sousa Santos (coordinador) Producir para vivir. Los caminos de la producción no capitalista. Fondo de Cultura Económica, México D.F.

Elizalde, A. (2013), “¿Otra economía para otra izquierda latinoamericana?”. América Latina en Movimiento 482: 18-24.

Escobar, A. (1995), Encountering Development, Princeton University Press, Princeton.

Esteva, G. (2000), “Desarrollo”, en Antropología del Desarrollo, Viola, A. (Comp.), Paidós, Barcelona, 67-103.

Evans, P. (1995), Embedded Autonomy, Princeton University Press, Princeton.

Galtung J., O’Brien, P., Preiswerk, R. (eds) (1980), Self-reliance. A strategy for Development,Bogle-L'Ouverture, Londres.

Gottdiener M., Hutchison R. (2006), The New Urban Sociology. Westview Press $3^{\circ}$ Edition. Boulder.

Hardt, N. (2009), The Commonwealth, Harvard University Press, Cambridge.

Hettne, B. (1982), Development theory and the Third World. SAREC, Helsingborg.

Harvey, D. (2010), The enigma of capital and the crises of capitalism, Oxford University Press, Nueva York.

Ídem (2012), The rebel cities. From the right to the city to the urban revolution, Verso, Londres. 
Ídem (2003), Espacios de esperanza, Akal, Madrid.

Hay, C. (2002), Political Analysis. A critical introduction. Palgrave, Nueva York.

Jessop, B. (1982), The capitalist State: Marxist theories and methods, Blackwell, Oxford.

Ídem (2007), State power, Polity, Cambridge.

Ídem (2008), El futuro del Estado Capitalista, Catarata, Madrid.

Ídem (2004), “Cultural political economy, the knowledge-based economy and the state" en Andrew Barry y Don Slater (eds.) The technological society, Routledge, Londres.

Ídem (2009), “Cultural political economy and critical policy studies”, Critical Policy Studies, vol.3, N³-4, 336-356.

Jessop, B.; Sum, N. (2001), "Pre-disciplinary and post-disciplinary perspectives” New Political Economy, 89-101.

Ídem (2006), Beyond the regulation approach: putting capitalist economies in their place. Edward Elgar, Londres.

Kiely, R. (1995), Sociology and Development. The impasse and beyond, University College of London Press, Londres.

Lazar, S. (2010), El Alto, Rebel city, Duke University Press, Durham.

Max-Neef, M. (1993), Desarrollo a escala humana, Editorial NordenComunidad, Montevideo.

ONU-Habitat (2012), Santiago, Chile.

Polanyi, Karl (1992), La gran transformación, Fondo de Cultura Económica, México, DF.

Quijano, A. (1998), La economía popular y sus caminos en América Latina, Mosca Azul, Lima.

Ribera-Fumaz R. (2009), "From urban political economy: rethinkingla culture and economy in and beyond the urban”, Progress in Human Geography, 2009, 33: 447-465.

Santos, B. (2005), Democratizar la democracia. Democratizar el Estado, CLACSO, Buenos Aires.

Santos, B.; Rodríguez, C. (2011), “Introducción. Para ampliar el canon de la 
producción” en Boaventura de Sousa Santos (coordinador) Producir para vivir. Los caminos de la producción no capitalista. Fondo de Cultura Económica, México D.F.

Sayer, A. (2000), Realism and Social Science. Sage, Londres.

Scott, A. J. (2000), The cultural economy of cities, Sage, Londres.

Storper, M. J. (1997), Regional Worlds, Guilford, Nueva York.

Short J. R. (2006), Urban theory. Palgrave, MacMillan, Londres.

Zibechi, R. (2012), Río de Janeiro: De la Ciudad Maravillosa la Ciudad Negocio, http://www.kaosenlared.net/america-latina/item/41859-rio-dejaneiro-de-laciudad-maravillosa-a-la-ciudad-negocio.html/.

Recibido: 23.07.2013

Aceptado: 15.05.2014 